\title{
Impact of the ash deposits from coal combustion on thermal conditions of the furnace pipes
}

\author{
Alexander Subbotin ${ }^{1,}$, Igor Razov ${ }^{2}$, Elena Popova ${ }^{1}$, Alexander Dolgih ${ }^{1}$, \\ and Anna Mazanik ${ }^{1}$ \\ ${ }^{1}$ National Research Tomsk Polytechnic University, 634050 Tomsk, Russia \\ ${ }^{2}$ Tyumen industrial University, 625000 Tyumen, Russia
}

\begin{abstract}
One of the problems of thermal power plants is the contamination of heating surfaces that arises during the boiler unit operation while combusting the solid fuel. The main part of the energy is consumed by pipes forming the furnace. Non-combustible mineral part of the fuel in the form of the ash and slag accumulates on the heating surfaces and thereby prevents heating of the working liquid. Therefore, boiler requires higher fuel consumption to maintain the operating conditions. Violation of the thermal conditions of heating surfaces in consequence of contamination causes the negative effects on metal pipes right up to failure. This problem is urgent due to the fact that information about the process of slagging and its effect on the thermal conditions of the heating surface operation enables the possibility to minimize the negative consequences. This possibility is achieved by adjusting the thermal conditions of the combustion process in the furnace with the periodic cleaning of the heating surfaces.
\end{abstract}

\section{Formulation of the problem}

One of the problems of thermal power plants is the contamination of heating surfaces that arises during the boiler unit operation [1]. Ash and slag accumulates on the heating surfaces and thereby prevents heat output. Therefore, boiler requires higher fuel consumption to maintain the operating conditions $[2,3]$. We consider a furnace pipe to have a layer of deposits on its surface. The diameter of the furnace pipe is much larger than its thickness $(60 \times 6 \mathrm{~mm})$. Thus, the influence of the curvature of the wall can be neglected [2]. In this case, the model of a flat homogeneous wall is implemented. The combustion process is adopted to be unsteady. For a steady-state solution we must specify a calculation time that will not affect the result $[4,5]$. We use the Fourier-Kirchhoff differential equation to describe the unsteady heat transfer by thermal conductivity:

$$
\rho \cdot c \cdot \frac{\partial T}{\partial t}=\frac{\partial}{\partial x}\left(\lambda \cdot \frac{\partial T}{\partial x}\right)+\frac{\partial}{\partial y}\left(\lambda \cdot \frac{\partial T}{\partial y}\right)+\frac{\partial}{\partial z}\left(\lambda \cdot \frac{\partial T}{\partial z}\right),
$$

\footnotetext{
* Corresponding author: subbot@tpu.ru
} 
where $\rho$ - density, $c$ - specific heat, $\lambda$ - coefficient of thermal conductivity.

Equation (1) describes temporal and spatial temperature variation at any point of the body. Since the considered model is a flat wall, and the heat flux occurs in one direction, we can move to the one-dimensional equation of non-stationary heat transfer:

$$
\rho \cdot c \cdot \frac{\partial T}{\partial t}=\frac{\partial}{\partial x}\left(\lambda \cdot \frac{\partial T}{\partial x}\right),
$$

To solve this problem, we apply the numerical method of finite differences. The solid body is represented as a plurality of nodes that are described by the algebraic equation of temperature. For nodes located on the boundary of a solid body we use separate equations for boundary conditions. As a result, algebraic equations are obtained for $\mathrm{n}$ nodes to be solved by computer-aided technologies $[4,5]$. When a single-layer wall is considered, one boundary condition is written for a contaminated wall, depending on the number of layers, two or more. By the iterative approximations, the values of the temperature gradient in the layers are found. At the boundary of contamination and metal there is a contact resistance, because of which two boundary conditions of the third kind at known ambient temperatures $T_{B 1}, T_{B 2}$, the contact resistance $r_{k}$ and the heat transfer coefficient to the steam-water mixture $\alpha_{2}$ are recorded.

The first layer:

$$
\begin{aligned}
& x=0, \quad-\lambda \frac{\partial T}{\partial x}=q_{C 1}, \quad t>0 ; \\
& x=\delta, \quad-\lambda \frac{\partial T}{\partial x}=\frac{1}{r_{k}} \cdot\left(T_{B 2}^{k}-T\right), \quad t>0,
\end{aligned}
$$

where $q_{c l}$ - heat flux density of thermal radiation:

$$
q_{C 1}=\varepsilon \sigma\left(\left(\frac{T_{1}}{100}\right)^{4}-\left(\frac{T_{B 1}}{100}\right)^{4}\right) x=0,
$$

The second layer:

$$
\begin{aligned}
& x=0, \quad-\lambda \frac{\partial T}{\partial x}=\frac{1}{r_{k}} \cdot\left(T_{B 1}^{k}-T\right), \quad t>0 ; \\
& x=0, \quad-\lambda \frac{\partial T}{\partial x}=\alpha_{2} \cdot\left(T_{B 2}-T\right), \quad t>0 .
\end{aligned}
$$

The temperatures $T_{B 1}^{k}, T_{B 2}^{k}$ at the boundary are :

The first layer:

$$
\begin{aligned}
& T_{1}^{j+1}=T_{2}^{j+1}+q_{C 1} \frac{h}{\lambda_{1}}, j=0,1,2, \ldots, \\
& T_{N}^{j+1}=\frac{T_{N-1}^{j+1}+B i_{1} \cdot T_{B 2}^{k}}{1+B i_{1}}, j=0,1,2, \ldots ;
\end{aligned}
$$


The second layer:

$$
\begin{aligned}
& T_{1}^{j+1}=\frac{T_{2}^{j+1}+B i_{1} \cdot T_{B 1}^{k}}{1+B i_{1}}, j=0,1,2, \ldots, \\
& T_{N}^{j+1}=\frac{T_{N-1}^{j+1}+B i_{2} \cdot T_{B 2}}{1+B i_{2}}, j=0,1,2, \ldots,
\end{aligned}
$$

Where $B i_{1}=\frac{h}{r_{k} \cdot \lambda_{1}}, B i_{2}=\alpha_{2} \cdot \frac{h}{\lambda_{2}}$ is the grid analog of Bio, $h$ is the step of the difference grid.

Inside the layer, to determine the temperature at each point, it is calculated both under the boundary conditions of the first kind:

$$
T_{i}^{j+1}=T_{i}^{j}+\frac{\lambda \cdot \tau}{\rho \cdot c \cdot h^{2}}\left(T_{i+1}^{j}-2 T_{i}^{j}+T_{i-1}^{j}\right)
$$

Boundary conditions of the third kind require the application of stringent conditions for the stability of the algorithm:

$$
\frac{\lambda \cdot \tau}{h^{2}}(1+B i)<0.5
$$

\section{Analysis of numerical results}

The algorithm for calculating the three layers is similar to the calculation of the two layers with addition of the new data. The initial data (Table 1) [6] were the thermal conductivity of annulus contamination. This contamination is caused by burning of lignite of the Kansko-Achinsk basin at Krasnoyarsk district (Russian Federation). The coefficient of thermal conductivity for all samples depends on the temperature and the composition of the contam-

\begin{tabular}{|c|c|c|c|c|c|c|c|c|}
\hline Layer & $\begin{array}{c}\text { Coefficient } \\
\text { of thermal } \\
\text { diffusivity, } \\
\mathrm{m}^{2} / \mathrm{s}\end{array}$ & $\begin{array}{l}\text { Coeffici } \\
\text { ent of } \\
\text { thermal } \\
\text { conducti } \\
\text { vity, } \\
\mathrm{W} /(\mathrm{mK}) \\
{[4]}\end{array}$ & $\begin{array}{c}\text { Thick } \\
\text { ness, } \\
\text { m }\end{array}$ & $\begin{array}{l}\text { Amou } \\
\text { nt of } \\
\text { points }\end{array}$ & $\begin{array}{l}\text { Calculati } \\
\text { on time, } \mathrm{s}\end{array}$ & $\begin{array}{c}\text { Flare } \\
\text { tempera } \\
\text { ture, } \mathrm{K}\end{array}$ & $\begin{array}{c}\text { Temperat } \\
\text { ure of the } \\
\text { working } \\
\text { fluid, K }\end{array}$ & $\begin{array}{c}\text { Temperat } \\
\text { ure of } \\
\text { liquid ash } \\
\text { state [5] }\end{array}$ \\
\hline Slag & $\begin{array}{c}8.33 \cdot 10^{-7}- \\
3.13 \cdot 10^{-6}\end{array}$ & $1-1.6$ & 0.001 & 20 & 600 & \multirow{3}{*}{2000} & \multirow{3}{*}{473} & \multirow{3}{*}{1503} \\
\hline $\begin{array}{c}\text { Conta } \\
\text { minati } \\
\text { on }\end{array}$ & $\begin{array}{c}4.74 \cdot 10^{-7}- \\
1.76 \cdot 10^{-6}\end{array}$ & $0.8-1.5$ & $\begin{array}{l}0.001- \\
0.003\end{array}$ & $20-80$ & 600 & & & \\
\hline Pipe & $1.38 \cdot 10^{-5}$ & 50 & 0.006 & 120 & 600 & & & \\
\hline
\end{tabular}
ination. For sulfate-bound deposits the coefficient of thermal conductivity is slightly less than $0.1 \mathrm{~W} / \mathrm{mK}$, for ferriferous it lies in the range of 1.4 to $1.5 \mathrm{~W} / \mathrm{mK}$.

Table 1. - Initial data.

The contact resistance according to the experimental data [6] is a function in terms of temperature: 


$$
r_{\mathrm{k}}=-7.247 \cdot 10^{-7} \cdot T+0.000647
$$

The heat transfer coefficient on the outside surface is $\alpha_{2}=4000 \mathrm{~W} /\left(\mathrm{m}^{2} \mathrm{~K}\right)$. The estimated time is 600 seconds and enables to come to a steady state.

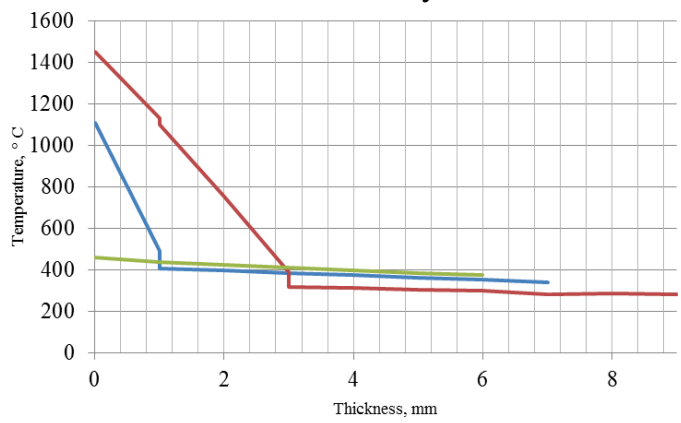

Fig. 1. Temperature distribution in the sediment layer (A).

This model does not take into account the heat sink by the steam-water mixture and is limited by the melting temperature of the slag. Different heat transfer acts if the slag turns into a fluid state. Therefore, a thin liquid non-flowing barely $1 \mathrm{~mm}$ layer of the slag was investigated over the impurities. Using the computer-aided technology, the developed algorithm is rewritten in the Pascal programming language. The results of the calculations are shown in Figures 1-3.

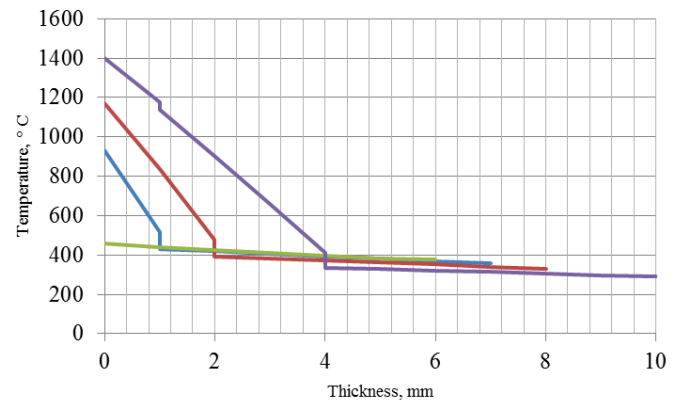

Fig. 2. Temperature distribution in the sediment layer (B).

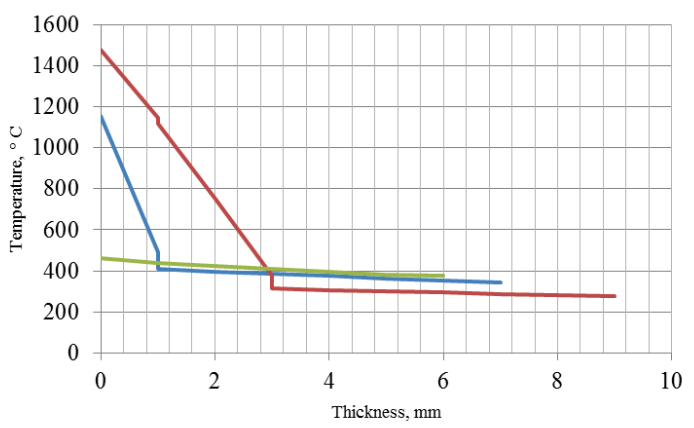

Fig. 3. Temperature distribution in the sediment layer (C).

Fig. 1-3 show that the temperature on the external surface rises sharply, but the temperature in the metal wall decreases significantly due to the contact resistance. Higher thickness of the contaminants causes the higher heat losses. The maximum thickness of contaminants 
reaches up to $0.5 \mathrm{~m}$. At this thickness value the heat exchange is minimum or absent depending on the composition of the deposits. Iron deposits (B) can have a large thickness with equal temperature distribution with sulfate-bound (A) and silicate (B). But this fact is useless, since they are hard to remove. Periodic cleaning will minimize the negative impact of pollution.

\section{References}

1. S.A. Khaustov, Y.A. Belousova, K.V. Buvakov, A.Y. Dolgih, R.N. Kulesh, 11th International Forum on Strategic Technology (IFOST 2016) Proceedings 2, 548 (2016)

2. K.Y. Shcherbakova, P.S. Gergelizhiu, B.V. Lebedev, MATEC Web Conf. 23, (2015)

3. K.Y. Orlova, B.V. Lebedev, MATEC Web Conf. 92, 01044 (2016)

4. G.V. Kuznetsov, V.Y. Polovnikov, J. Eng. Thermophys. 20, 2 (2011)

5. G.V. Kuznetsov, A.E. Sitnikov, Inzhenerno-Fizicheskii Zhurnal, 75, 4 (2002) [in Russian]

6. A.S. Zavorin, Y.Y. Rakov, Therm. Eng. 47, 12 (2000) 